\title{
Enhance the Immune Checkpoint Inhibitors Efficacy with Radiotherapy Induced Immunogenic Cell Death: A Comprehensive Review and Latest Developments
}

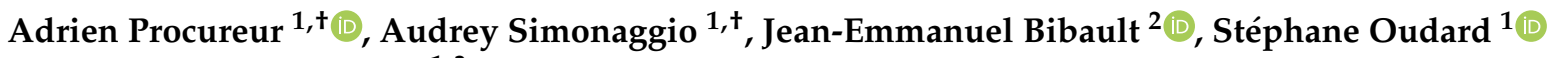 \\ and Yann-Alexandre Vano ${ }^{1,3, *}$
}

1 Hôpital Européen Georges Pompidou, Service d'Oncologie Médicale, Assistance Publique-Hôpitaux de Paris (AP-HP) Paris-Centre, F-75015 Paris, France; adrien.procureur.oncology@gmail.com (A.P.); audrey.simonaggio@aphp.fr (A.S.); stephane.oudard@aphp.fr (S.O.)

2 Hôpital Européen Georges Pompidou, Service d'Oncologie Radiothérapie, Assistance Publique-Hôpitaux de Paris (AP-HP) Paris-Centre, F-75015 Paris, France; jean-emmanuel.bibault@aphp.fr

3 Centre de Recherche des Cordeliers, Sorbonne Université, Inserm, Université de Paris, F-75006 Paris, France

* Correspondence: yann.vano@aphp.fr

+ Authors contributed equally to this work.

Citation: Procureur, A.; Simonaggio, A.; Bibault, J.-E.; Oudard, S.; Vano,

Y.-A. Enhance the Immune

Checkpoint Inhibitors Efficacy with Radiotherapy Induced Immunogenic Cell Death: A Comprehensive Review and Latest Developments. Cancers 2021, 13, 678. https://doi.org/

10.3390/cancers13040678

Academic Editor: Alberto Anel

Received: 31 December 2020

Accepted: 2 February 2021

Published: 8 February 2021

Publisher's Note: MDPI stays neutral with regard to jurisdictional claims in published maps and institutional affiliations.

Copyright: (C) 2021 by the authors. Licensee MDPI, Basel, Switzerland. This article is an open access article distributed under the terms and conditions of the Creative Commons Attribution (CC BY) license (https:// creativecommons.org/licenses/by/ $4.0 /)$.
Simple Summary: Efficient antitumoral immune response is conditioned by a regulated cell death called immunogenic cell death. Many immunologic cell death inducers are currently used in cancer treatment. Among them, radiation therapy is an adaptable, well tolerated and widely used modality of treatment in modern oncology. Moreover, there is growing evidence for synergistic mechanisms between radiotherapy and immune checkpoint inhibitors. Although pre-clinical concepts are numerous, robust clinical evidence is scarce. Radioimmunology is a rapidly evolving discipline with several ongoing clinical trials. In this review, we (i) explain the rationale behind radiotherapy and immune checkpoint-inhibitor association in the light of the most recent knowledge, (ii) provide the results of the latest clinical trials evaluating radiation therapy and immune checkpoint association and (iii) explore the future directions of radioimmunology research.

Abstract: The immunogenic cell death (ICD) is defined as a regulated cell death able to induce an adaptive immunity. It depends on different parameters including sufficient antigenicity, adjuvanticity and favorable microenvironment conditions. Radiation therapy (RT), a pillar of modern cancer treatment, is being used in many tumor types in curative, (neo) adjuvant, as well as metastatic settings. The anti-tumor effects of RT have been traditionally attributed to the mitotic cell death resulting from the DNA damages triggered by the release of reactive oxygen species. Recent evidence suggests that RT may also exert its anti-tumor effect by recruiting tumor-specific immunity. RT is able to induce the release of tumor antigens, to act as an immune adjuvant and thus to synergize with the anti-tumor immunity. The advent of new efficient immunotherapeutic agents, such as immune checkpoint inhibitors (ICI), in multiple tumor types sheds new light on the opportunity of combining RT and ICI. Here, we will describe the biological and radiobiological rationale of the RT-induced ICD. We will then focus on the interest to combine RT and ICI, from bench to bedside, and summarize the clinical data existing with this combination. Finally, RT technical adaptations to optimize the ICD induction will be discussed.

Keywords: radiotherapy; radioimmunotherapy; immunogenic cell death; immune checkpoint inhibitors; combination therapy; cancer treatment

\section{Introduction}

Cancer is the second leading cause of death worldwide and the first in high-income countries [1]. Last decade, the development of immune-checkpoint inhibitors (ICI) has radically changed the clinical practice in multiple tumor types. For instance, Pembrolizumab, a 
humanized IgG4/kappa anti-PD1, is indicated as frontline therapy for advanced melanoma, for PD-L1 $\geq 50 \%$ advanced non-small cell lung carcinoma and for cisplatin-ineligible patient with advanced urothelial cancer. The Food and Drug Administration (FDA) has approved this ICI both for mismatch repair deficient tumors and for high mutational burden tumors, regardless of histology. However, apart from the above cases, most of the patients treated with ICI monotherapy will not have any benefit [2]. One of the reasons is the lack of efficient preexisting immune response.

The immune response must be initiated with a unique type of programmed cell death: the immunogenic cell death (ICD). ICD leads to the release of damage-associated molecular patterns (DAMPs) that is required for dendritic cell maturation and activation. Radiation therapy (RT) is a powerful tool to induce ICD and exhibits many advantages: its safety profile is well known; it could be easily associated with various other therapeutics and RT schedule and sequences could be optimized to improve its immune effects. Rare tumoral regression outside the radiation field had been reported for a long time now [3]. That phenomenon, better known as abscopal effect, is related to the induction of systemic $\mathrm{CD}^{+}$-dependent immune response [4-6]. Today, the association of RT and ICI is relevant, especially because of the up-regulation of checkpoint proteins after tumor irradiation. On the other hand, like most of the ICD inducers, RT has been developed from the paradigm of maximum tolerated dose, not immune-optimized schedule [7]. Yet, it is now clear that greater cytotoxicity is not systematically associated with optimal immunogenicity [8]. The optimal regimen, dose per fraction and ICI association remain to be defined and evaluated within large cohorts.

The objective of this review is to provide an up-to-date overview of the RT-ICI association. First, we will describe the biological rational of the RT-induced ICD, and its potential synergy with ICI. Then we will summarize the main results of combination trials (from bench to bedside). Finally, we will discuss different strategies and RT technical adaptation to improve the efficacy of RT-ICI combination.

\section{The Biology of Radiotherapy-Induced ICD}

\subsection{ICD in Oncology}

ICD is defined as a form of regulated cell death that is sufficient to activate an adaptative immune response in immunocompetent syngeneic hosts [9]. How does ICD lead to efficient antitumoral-response? The induction of adaptative immune response depends on three parameters: antigenicity, adjuvanticity and microenvironment.

In physiological condition, apoptosis (and in specific settings necroptosis) are more tolerogenic than immunogenic regulated cell deaths [10]. Moreover, they fail to induce immune response in the context of central tolerance. Indeed, their antigens are expressed by thymic epithelium during negative selection of lymphocytes. While cancer cells display tumor-associated antigens (neo-antigens or overexpressed embryonic antigens) that are sufficient to lead to T-cell clonal expansion. Despite the intrinsic antigenicity of tumor cells, the immune response remains conditioned by the recruitment, the maturation, and the activation of antigen-presenting cell (APC).

Adjuvanticity refers to a spatiotemporal coordinated and highly specific release or exposure of danger signals required to fully activate APC [7]. It is mediated by the release of damage-associated molecular patterns (DAMPs) allowed by ICD. ICD is triggered by the endoplasmic reticulum stress and/or reactive oxygen species (ROS)-stress [11]. It is characterized by three hallmarks: calreticulin (CALR) exposure on the cell membrane, adenosine triphosphate (ATP) secretion and high-motility group box 1 (HMGB1) release into the extracellular space [12,13]. HSP70 and HSP90 exposure are also involved in ICD.

Lastly, the tumor microenvironment conditions influence dramatically both the priming and the effector phase of the antitumoral-response [14]. An immunosuppressive microenvironment disrupts the initiation of immune response through ICD [15]. 


\subsection{Radiotherapy as an ICD Inducer}

Antitumoral effects of RT is not restricted to induction of double-strand DNA breaks. Ionized radiation induces ROS-stress that leads to ICD through CARL exposition, ATP and HMGB1 release [14,16]. Ionized radiation promotes a pro-inflammatory environment through the release of chemokines and adhesion molecules leading to APC recruitment [17]. Besides, IFN type I secretion through STING-signaling pathway is essential to radiationinduce antitumor response [18]. T-cell functions and infiltration are also improved, respectively with enhanced MHC class I expression over tumor cells and with vascular remodeling $[19,20]$.

Conversely, for a second time, these chemokines recruit myeloid-derived suppressor cells (MDSC) and regulatory T cells (Treg) that promote the immunosuppressive microenvironment [21,22]. IFN $\gamma$ secretion from $\mathrm{CD}^{+} \mathrm{T}$-cell, consecutively to RT fractionation, upregulates PD-L1, leading to T cell and NK exhaustion [23]. ROS also polarized tumorassociated macrophages to alternatively activated macrophages (M2) leading to PD-L1 upregulation and immunosuppressive cytokine secretion [24]. For most patients with metastatic cancer, focal radiotherapy as a standalone treatment fails to achieve an efficient systemic immune response, mainly because of co-inhibitory receptors upregulation and TGF $\beta$ secretion from recruited immunosuppressive cells [25]. The abscopal effect remains rare. PD-L1 seems to play a critical role in post-irradiation immunomodulation [21,26]. For example, PD-L1 is associated with radiation resistance in patient derived cell line model from head and neck cancer [27]. Accumulating evidence, both pre-clinical and clinical, indicates that ICI association with radiotherapy is promising to overcome the radio-induced immunosuppressive tumoral microenvironment $[28,29]$.

\subsection{Radiotherapy and ICI}

Irradiated tumor microenvironment is enriched with several immunosuppressive cells; MDSC expresses PD-L1 and inhibit CD8 ${ }^{+}$T-cell and NK-cell activity; Treg exhibits high levels of CTLA4 and PD-L1 and compromise local immune response [22]. ICI restores not only cytotoxic activity of T-cell inside the irradiated-tumoral microenvironment, but it also reinvigorates APC activity and converts the irradiated-tumor in an effective in situ vaccine [30]. A systemic activity could be obtained. In pre-clinical models, Ipilimumab (IgG1 anti-CTLA4 antibody) induces Treg depletion and raises TCD8 ${ }^{+} /$Treg ratio [22]. Anti-PD-1 or anti-PD-L1 restore CD8 ${ }^{+}$T-cell cytotoxicity and indirectly causes MDSC depletion, probably via TNF secretion [21]. RT-induced ICD, RT tumoral microenvironment reprogramming, and ICI effects are summarized in Figure 1.

Nevertheless, abscopal effect remains hardly reproducible in clinical practice. Above all because optimal RT schedule, dose rate and fractionation are not clearly defined. Until now, radiotherapy has been developed on the basis of maximum tolerated dose paradigm to obtain the best radiation dose delivery. However, maximum tolerated dose is not adapted to maximize the RT pro-immunogenic properties [7]. A paradigm shift is therefore necessary and new protocols are required.

Several clinical trials have evaluated the benefits of ICI association with RT. The results highly depend on tumoral subtypes. 


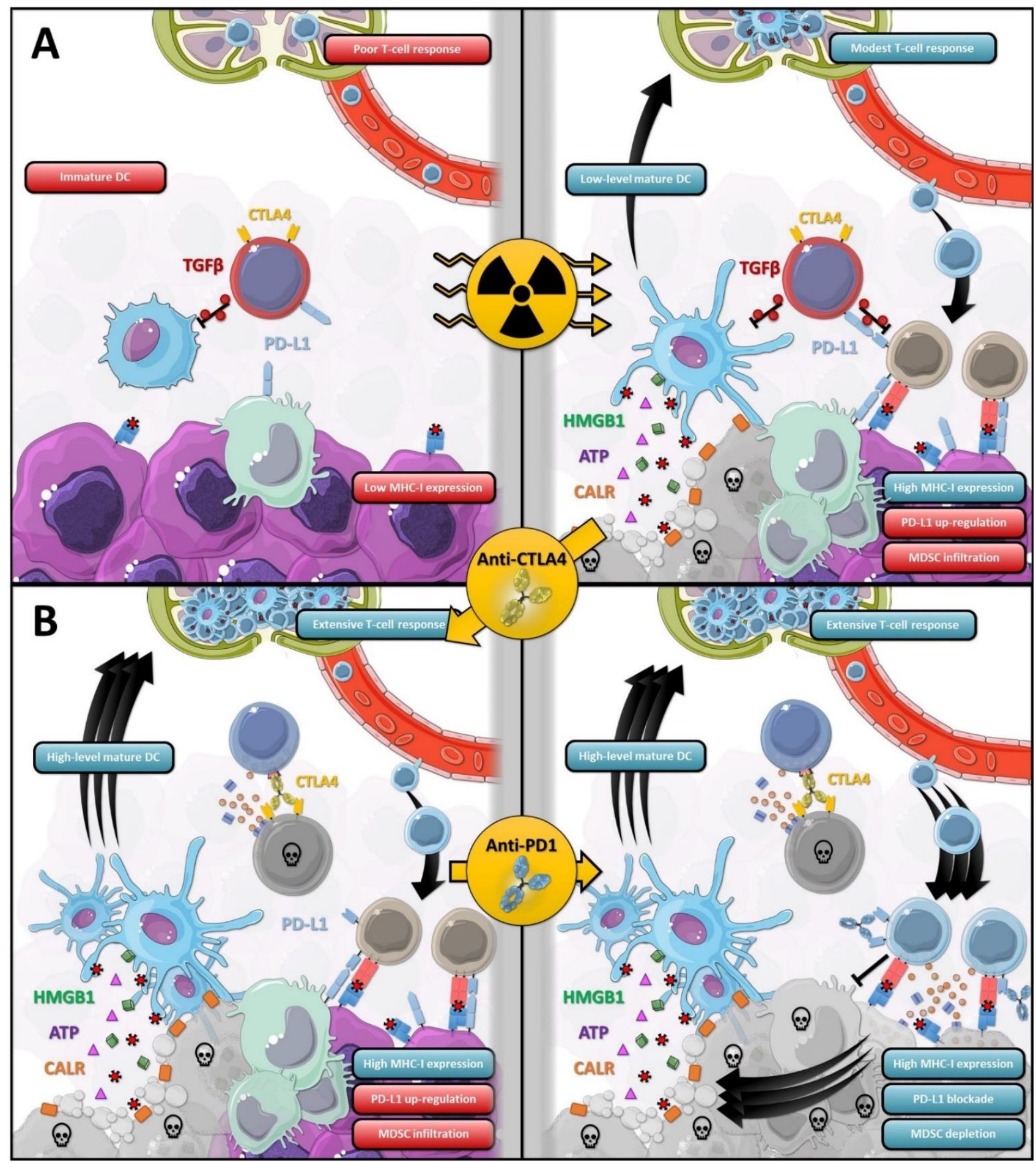

Figure 1. The biological consequences of RT and the synergism effects of RT-ICI association. (A) RT induce ICD leading to DC maturation and activation. However, DC activation is limited by Treg (red cell) through TGF $\beta$ secretion. Despite the MHC-1 upregulation, CD8 ${ }^{+}$T-cells remain inhibited by RT-related PD-L1 upregulation, MDSC infiltration and TGF $\beta$ secretion. (B) Anti-CTLA4 antibodies induce Treg depletion by ADCC, and DC activity is increased. On the other hand, $\mathrm{CD}^{+}$T-cells are still inhibited by PD-1/PD-L1 axis. It is only through the addition of anti-PD-1 or anti-PD-L1 antibodies that an effective immune response can be restored. A virtuous cycle is set up. ATP, adenosine triphosphate; CALR, calreticulin; CTLA4, cytotoxic T-lymphocyte-associated protein 4; DC, dendritic cell; HMGB1, high mobility group box 1; MDSC, myeloid-derived suppressor cell; MHC-1, major histocompatibility complex class 1; PD-L1, programmed death-ligand 1; TGF $\beta$, transforming growth factor beta. This figure was created using Servier Medical Art templates (Creative Common Attribution 3.0), https:/ / smart.servier.com (access on 29 December 2020). 


\section{RT and ICI Synergism: Emerging Clinical Evidence Related to Efficacy and Safety}

Given the historical development of ICIs in melanoma and non-small cell lung carcinoma (NSCLC), most robust clinical results of the combination of ICI and radiotherapy have been reported for these two cancer subtypes. Data are also emerging for head and neck, esophageal and urologic cancers. The following is a non-exhaustive summary of main available data related to the feasibility and the efficacy of such combination, from phase I clinical trials to phase II/III clinical trials. Main prospective data related to the efficacy of ICI-RT combination are summarized in Table 1.

Table 1. Summary of main prospective available data related to the efficacy of radiotherapy and ICI combination.

\begin{tabular}{|c|c|c|c|c|}
\hline Population & Reference & Phase & Intervention & Results \\
\hline $\begin{array}{l}\text { Locally advanced } \\
\text { NSCLC }\end{array}$ & [31] & I & Pembrolizumab + chemoradiotherapy & $\begin{array}{l}6-\text { mo PFS rate }=81 \% \\
12-\text { mo PFS rate }=69.7 \% \\
\text { Median PFS }=18.7 \mathrm{mo}\end{array}$ \\
\hline $\begin{array}{l}\text { Locally advanced } \\
\text { NSCLC }\end{array}$ & PACIFIC [32-34] & III & $\begin{array}{c}\text { Durvalumab (12 mo) as consolidation therapy vs. } \\
\text { placebo (12 mo) }\end{array}$ & $\begin{array}{l}\text { ORR }=28.4 \% \text { vs. } 16.0 \%(p<0.001) \\
\text { Median PFS }=16.8 \text { mo vs. } 5.6 \\
(p<0.001) \\
36 \text { months OS }=55.3 \% \text { vs. } 43.5 \%\end{array}$ \\
\hline $\begin{array}{l}\text { Locally advanced } \\
\text { NSCLC }\end{array}$ & [35] & II & $\begin{array}{l}\text { Chemoradiation + pembrolizumab }(12 \mathrm{mo}) \text { as } \\
\text { consolidation therapy }\end{array}$ & $\begin{array}{c}\text { Time to metastatic disease }=30.7 \mathrm{mo} \\
\text { PFS }=18.7 \mathrm{mo} \\
\text { OS }=35.8 \mathrm{mo}\end{array}$ \\
\hline $\begin{array}{l}\text { 1-4 metastatic sites } \\
\text { NSCLC }\end{array}$ & [36] & II & $\begin{array}{l}\text { Pembrolizumab within } 4-12 \text { weeks after locally } \\
\text { ablative therapy }\end{array}$ & $\begin{array}{l}\text { Median PFS from the start of locally } \\
\text { ablative therapy }=19.1 \text { mo }\end{array}$ \\
\hline $\begin{array}{l}\text { Locally advanced } \\
\text { HNSCC }\end{array}$ & [37] & I & $\begin{array}{c}\text { Cisplatin-based chemoradiotherapy }+ \\
\text { pembrolizumab (concurrently + as maintenance) }\end{array}$ & $\begin{array}{l}\text { CR }(\mathrm{HPV}+)=85.3 \% \\
\mathrm{CR}(\mathrm{HPV}-)=78 \%\end{array}$ \\
\hline $\begin{array}{l}\text { Locally advanced } \\
\text { HNSCC }\end{array}$ & $\begin{array}{l}\text { JAVELIN H\&N } \\
100[38]\end{array}$ & III & $\begin{array}{l}\text { Avelumab }+ \text { chemoradiotherapy }+ \text { avelumab } \\
\text { maintenance vs. Placebo }+ \text { chemoradiotherapy }+ \\
\text { placebo maintenance }\end{array}$ & $\begin{array}{l}\text { At the time of the interim analysis: } \\
\text { no significant improvement in PFS or } \\
\text { OS }\end{array}$ \\
\hline $\begin{array}{l}\text { Locally advanced } \\
\text { HNSCC } \\
\text { (cisplatin-unfit } \\
\text { patients) }\end{array}$ & PembroRad [39] & II & $\begin{array}{l}\text { Once-daily RT up to } 69.9 \text { Gy associated with: } \\
\text { Cetuximab vs. pembrolizumab }\end{array}$ & $\begin{array}{l}\text { Loco-regional-control at } 15 \mathrm{mo}=59 \% \\
\text { vs. } 50 \%(p=0.91) \\
24-\mathrm{mo} \text { PFS }=40 \% \text { vs. } 42 \%(p=0.41) \\
24-\mathrm{mo} \text { OS }=55 \% \text { vs. } 62 \%(p=0.5)\end{array}$ \\
\hline Stage III/IV RCC & $\begin{array}{l}\text { RADVAX RCC } \\
{[40]}\end{array}$ & II & $\begin{array}{c}\text { Nivolumab + ipilimumab + SBRT (40-50 Gy in } 5 \\
\text { fractions) }\end{array}$ & $\begin{array}{c}\mathrm{PR}=56 \% \\
\mathrm{SD}=24 \% \\
\mathrm{PD}=16 \% \\
12-\mathrm{mo} \text { PFS rate }=36 \%\end{array}$ \\
\hline 2nd or 3rd line RCC & NIVES [41] & II & $\begin{array}{l}\text { Nivolumab }+ \text { SBRT }(10 \text { Gy } \times 3 \text { fractions } 7 \text { days } \\
\text { after the 1st infusion of nivolumab) }\end{array}$ & $\begin{array}{c}\text { ORR }=17.4 \% \\
12-\text { mo median OS }=73.4 \%\end{array}$ \\
\hline $\begin{array}{l}\text { Metastatic } \\
\text { Melanoma }\end{array}$ & [42] & I & $\begin{array}{c}\text { RT (6-8 Gy, 2-3 times) followed by ipilimumab } \\
\text { injections }\end{array}$ & $\begin{array}{l}\mathrm{PR}=18 \% \\
\mathrm{SD}=18 \%\end{array}$ \\
\hline $\begin{array}{l}\text { Metastatic } \\
\text { Melanoma }\end{array}$ & [43] & I & $\begin{array}{c}\text { Ipilimumab + RT (between 18-50 Gy, in 1-15 } \\
\text { fractions) }\end{array}$ & $\begin{array}{c}\text { Clinical benefit }=50 \% \\
P R=15 \% \\
C R=15 \%\end{array}$ \\
\hline $\begin{array}{l}\text { Metastatic } \\
\text { Melanoma }\end{array}$ & [44] & I & $\begin{array}{l}\text { Nivolumab + ipilimumab + extracranial RT ( } 30 \\
\text { Gy in } 10 \text { fractions or } 27 \text { Gy in } 3 \text { fractions) }\end{array}$ & $\begin{array}{l}\text { PR outside of the irradiated volume: } \\
6 / 19 \text { No progression of irradiated } \\
\text { metastases }\end{array}$ \\
\hline
\end{tabular}

Abbreviations: mo: months; NSCLC: non-small cell lung carcinoma; ORR: objective response rate; CR: complete response; PR: partial response; OS: overall survival; PD: progressive disease; PFS: progression-free survival; RCC: renal cell carcinoma; RT: radiation therapy; SD: stable disease; SBRT: Stereotaxic Body Radiation Therapy.

\subsection{Efficacy of Combined ICI and Radiation Therapy}

\subsubsection{Locally Advanced NSCLC (LA-NSCLC)}

Focusing on NSCLC, several preclinical and clinical trials have demonstrated that ICI-RT combination could induce synergistic effect and improve survival outcome. However, the optimal RT parameters remain unknown, in particular the sequencing modes of combination therapy: sequential, induction or concurrent therapy. Dozens of trials are ongoing to find the best combination strategy [45]. Colorectal models offered some answers 
to this issue. Two pre-clinical studies demonstrated increased benefit with concurrent ICI and RT administration. Dovedi et al. demonstrated that concomitant but not sequential administration with fractionated radiotherapy improved survival. Mechanistically, after delivery of RT, IFN $\gamma$ produced by $\mathrm{CD}^{+} \mathrm{T}$ cells was responsible for mediating PD-L1 upregulation on tumor cells [46].

Concomitant schedule: most trials assessing the efficacy of a concomitant schedule in LA-NSCLC are still ongoing. Jabbour et al. recently reported in JAMA oncology the results of a phase I trial evaluating PD-1 inhibition concurrently with definitive chemoradiotherapy for NSCLC [31]. Twenty-one patients received pembrolizumab combined with concurrent chemoradiotherapy. Promising 6 and 12 months PFS of 81\% and 69.7\% were observed, motivating larger prospective study. Median PFS was 18.7 months, partial response was observed in $74 \%$ of patients and overall response in 16\% [31]. Spaas and Lievens recently summarized ongoing trials evaluating immunotherapy-radiotherapy combinations in NSCLC [47].

Among the largest study, we can highlight:

1. Phase III-PACIFIC-4 (NCT03833154) evaluating durvalumab vs. placebo with Stereotactic Body Radiation Therapy (SBRT) in early-stage unresectable NSCLC (estimated enrollment: 706 patients).

2. Phase II-KEYNOTE-799 (NCT03631784) evaluating pembrolizumab in combination with chemoradiotherapy in stage III NSCLC (enrollment: 216 patients).

3. Phase II-NCT03663166 evaluating radiation and chemotherapy with ipilimumab followed by nivolumab for stage III unresectable NSCLC (estimated enrollment: 50 patients).

Sequential schedule: the phase III clinical trial PACIFIC compared durvalumab (at a dose of $10 \mathrm{mg} / \mathrm{kg}$ intravenously) or placebo every 2 weeks for up to 12 months as consolidation therapy in 713 stage III NSCLC patients with no progressive disease after two or more platinum-based chemoradiotherapy. The delay between completion of the last radiation dose and the first durvalumab administration was 1 to 42 days. Progressionfree survival was significantly improved in the durvalumab arm with a median PFS of 16.8 months (95\% CI, 13-18.1) versus 5.6 (95\% CI, 4.6-7.8) with placebo (HR 0.52; 95\% CI, 0.42 to $0.65 ; p<0.001)$. The response rate was higher $(28.4 \%$ vs. $16.0 \% ; p<0.001)$, and the median duration of response was longer (72.8\% vs. $46.8 \%$ of the patients had an ongoing response at 18 months) in the durvalumab arm [33,34]. Updated OS data confirmed the long-term benefit with a 36-months OS rate of 55.3\% versus $43.5 \%$ for Durvalumab arm [32]. Interestingly, examining the timing when durvalumab was started relative to the end of chemoradiotherapy suggests that starting ICI within 14 days after completion of chemoradiotherapy was associated with a greater PFS: HR 0.39 (95\% CI, 0.26-0.58) vs. 0.63 (95\% CI, 0.49-0.80).

Assessing similar strategy, Durm et al. recently reported the results of a phase II trial of consolidation pembrolizumab following chemoradiation for patients with unresectable stage III NSCLC. Both times to metastatic disease, PFS and OS were improved in comparison with historical controls with respectively median value of 30.7, 18.7 and 35.8 months [35].

\subsubsection{Metastatic NSCLC}

Concurrent and sequential ICI/RT combinations are currently under investigation, both in metastatic and oligometastatic disease. Baulm et al. have recently reported the results of a phase II single-arm study evaluating pembrolizumab within 4 to 12 weeks after completion of locally ablative therapy for oligometastatic ( $\leq 4$ metastatic sites) NSCLC. No new safety signals or reduction of quality of life was observed. Median PFS from the start of locally ablative therapy was 19.1 months (95\% CI, 9.4-28.7), significantly greater than the historical median of 6.6 months $(p=0.005)$ [36]. The main ongoing phase III trials are listed in Table 2. Interestingly, several trials are evaluating a potential re-induction effect 
after initial response with immune therapy with RT. Patients get radiotherapy on a lesion while continuing the same ICI (NCT03406468, NCT03224871).

Table 2. Main ongoing phase III trials with ICI/RT combinations in advanced NSCLC.

\begin{tabular}{cccccc}
\hline Trial Name & Study Phase & Enrollment & Stage & Experimental/Control Arm & Status \\
\hline NCT03867175 & Phase III & 116 & III & $\begin{array}{c}\text { Consolidative immunotherapy with pembrolizumab }+/- \\
\text { SBRT after first line systemic therapy }\end{array}$ & Recruiting \\
\hline $\begin{array}{c}\text { NCT03774732 } \\
\text { NIRVANA-lung }\end{array}$ & Phase III & 688 & III/IV & Anti PD1 +/ - RT 15 d after the beginning of ICI, 18 Gy & Recruiting \\
\hline $\begin{array}{c}\text { NCT03391869 } \\
\text { LONESTAR }\end{array}$ & Phase III & 116 & IV & $\begin{array}{c}\text { Local consolidation therapy: 14 d after nivolumab + } \\
\text { ipilimumab for ICI-naive patients with metastatic NSCLC }\end{array}$ & Recruiting \\
\hline
\end{tabular}

\subsubsection{Melanoma}

Ipilimumab and brain radiotherapy: given the frequency of brain metastases in melanoma patients, first data related to the combination of ICI and radiotherapy concerned brain radiotherapy. Reports are mainly retrospective with a potential bias on patients selection. Two retrospective studies reported an increased median survival for patients receiving both ipilimumab and radiotherapy. In the Yale University study, patients receiving both Ipilimumab and RT had a median survival of 21.3 months ( $95 \%$ CI, 6.4-26.7) vs. 4.9 months (95\% CI, 3.3-10.4) for those who did not receive ipilimumab $(p=0.044)$. In the MSKCC study, the delivery of radiotherapy during ipilimumab was also associated with an increase survival. Patients treated with RT before or during ipilimumab had better OS than those treated with RT after ipilimumab (1-year OS: $65 \%$ vs. $56 \%$ vs. $40 \%, p=0.008$ ) $[48,49]$.

Ipilimumab and extra cranial radiotherapy: in a recent review, Kabiljo et al. reported two prospective trials combining external beam radiotherapy with ipilimumab in melanoma [50]. Both studies lack a control group receiving ipilimumab only but nevertheless response rate were higher compared with previous prospective cohort. In both studies, the combination was well tolerated. Radiation schedules were different. In the first one, metastases were irradiated with 6 to $8 \mathrm{~Gy}, 2$ or 3 times followed by ipilimumab injections. Eighteen percent of patients had partial response and $18 \%$ had stable disease [42]. In the second, radiation therapy (determined by the treating radiation oncologist, ranged between 18 and 50 Gy in 1 to 15 fractions) was performed concomitantly with ipilimumab. Fifteen percent of patients achieved complete response with a median follow-up of 55 weeks and $15 \%$ achieved a partial response [43].

Anti PD-1 and radiotherapy: a combination of anti-PD1 therapy and brain radiation therapy was also investigated in numerous retrospective trials. A recent meta-analysis led by Strokes et al. revealed a significant benefit to combine either anti CTLA- 4 or anti PD-1 therapy with radiation therapy versus radiation therapy alone [51]. Another metaanalysis led by Qian et al. revealed that PD-1 inhibition was more effective than CTLA-4 inhibition, both combined with radiation therapy [52]. In this meta-analysis, response of melanoma brain metastasis was studied according to the relative timing and the type of ICI. All 75 melanoma patients were treated with Gamma Knife to a median of 20 Gy (range: 12-24 Gy). Concurrent stereotactic surgery and immunotherapy (i.e., within 4 weeks) were associated with an improved reduction in the lesion volume at 6 months in comparison with non-concurrent therapy $(-94.9 \%$ vs. $-66.2 \%, p<0.001)$. Similar results were observed after 1.5 and 3 months. The median reduction in the lesion volume was significantly higher with anti PD- 1 than with anti CTLA4 at 6 months $(-95.1 \%$ vs. $-75.9 \%, p<0.001)$. Similar results were observed after 1.5 and 3 months. The superiority of PD-1 inhibition has recently been confirmed in several retrospective studies [53-56].The first prospective phase I trial of nivolumab, ipilimumab and extracranial radiotherapy (30 Gy in 10 fractions or $27 \mathrm{~Gy}$ in 3 fractions) in patients with advanced melanoma demonstrated that RT-nivolumabipilimumab combination appears safe compared with historical data of nivolumab and ipilimumab alone. Randomized studies are ongoing to assess whether RT increases the efficacy of ICI [44]. 


\subsubsection{Head and Neck}

ICI, nivolumab and pembrolizumab, used alone or in combination with chemotherapy, are now standard of care for recurrent or metastatic head and neck squamous cell carcinoma (HNSCC) in first- and second-line settings (CheckMate 141, KEYNOTE 012, KEYNOTE 048). Despite these therapeutic advances, response rate remains low and combination strategies to enhance ICI efficacy are under investigation.

In locoregionally advanced HNSCC, chemoradiotherapy (CRT) remains the standard of care. However, despite this multimodal therapy, locally advanced HNSCC (LA-HNSCC) recurs in many patients. Prospective studies evaluating the addition of ICI to CRT for non-metastatic advanced HNSCC are lacking. Although promising phase I studies with complete response rates up to $85.3 \%$ and $78 \%$ for HPV+ and HPV- locally advanced (LA) HNSCC treated with pembrolizumab and CRT, first results of phase II and III studies were disappointing [37]. Interim analysis of phase III Javelin 100, evaluating a regimen of avelumab plus chemoradiotherapy (CRT) followed by avelumab maintenance over placebo plus CRT and placebo maintenance for LA-HNSCC were presented during the 2020 ESMO annual meeting. No significant improvement in PFS was observed with the addition of avelumab (HR $=1.21,95 \%$ CI: $0.93-1.57, p=0.92)$ [38]. The GORTEC 2015-01 "PembroRad" randomized trial, led by J. Bourhis, has evaluated once-daily IMRT up to 69.96 Gy concomitant with cetuximab $\left(400 \mathrm{mg} / \mathrm{m}^{2}\right.$ loading dose and $250 \mathrm{mg} / \mathrm{m}^{2}$ weekly) or pembrolizumab (Pembro-RT arm: $200 \mathrm{mg}$ Q3W during RT) for non-operated stage III-IVa-b and cisplatin unfit patients. Neither loco-regional control (LRC) nor PFS nor OS were improved with the anti-PD1 pembrolizumab. LCR at 15 months was $59 \%$ in cetuximabRT arm versus 50\% in pembrolizumab-RT arm (OR $=1.05$ (95\% CI: 0.43-2.59, $p=0.91$ ). 2-years PFS and 2-years OS were respectively $40 \%$ vs. $42 \%$ (HR $=0.83,95 \%$ CI: $0.53-1.29$, $p=0.41$ ) and $55 \%$ vs. $62 \%$ in the cetuximab-RT arm and in the Pembrolizumab-RT arm [39]. Other phase II and III studies are evaluating the combination of radiation therapy and immunotherapy, both in early and advanced settings [57]. The main studies are listed in Table 3.

Table 3. Main ongoing clinical trials with ICI/RT combinations in advanced HNSCC.

\begin{tabular}{|c|c|c|c|c|c|}
\hline Trial Name & Study Phase & Enrollment & Stage & Experimental/Control Arm & Status \\
\hline NCT03380394 & Phase II & 122 & III & RT + pembrolizumab vs. RT + cisplatin & Recruiting \\
\hline NCT03673735 & Phase III & 650 & III & $\begin{array}{c}\mathrm{RT}+\text { cisplatin }+/ \text { - durvalumab HPV-negative } \\
\text { HNSCC only }\end{array}$ & Not yet recruiting \\
\hline NCT02999087 & Phase III & 688 & III & $\begin{array}{l}\mathrm{RT}+\text { cisplatin vs. } \mathrm{RT}+\text { cetuximab vs. } \mathrm{RT}+ \\
\text { cetuximab + avelumab }\end{array}$ & Recruiting \\
\hline NCT03349710 & Phase III & 1046 & III/IV & $\begin{array}{l}\mathrm{RT}+\text { cetuximab }+/- \text { nivolumab vs. } \mathrm{RT}+ \\
\text { cisplatin }+/- \text { nivolumab }\end{array}$ & Recruiting \\
\hline NCT03426657 & Phase II & 120 & III & $\mathrm{RT}+$ durvalumab + tremelimumab & Not yet recruiting \\
\hline
\end{tabular}

\subsubsection{Other Malignancies}

In esophageal cancer, chemoradiation remains the standard of care for unresectable disease with a poor prognosis. Since nearly half of these patients demonstrate PD-L1 expression, several ongoing phase I-II trials are evaluating the safety and the efficacy of chemoradiation and ICI combination, both in locally advanced, metastatic settings (NCT03377400, NCT03437200, NCT02642809) or neoadjuvant settings (NCT02735239, NCT02844075, NCT03064490).

In renal cell carcinoma (RCC), data related to the putative benefit of RT in combination with ICI are emerging. The preliminary results of the single-arm trial RADVAX RCC trial were presented at the 2020 Genitourinary Cancers Symposium. Twenty-five metastatic RCC patients had one of their metastases treated with SBRT (40-50 Gy in 5 fractions) in combination with ipilimumab and nivolumab during an induction phase followed by nivolumab alone. Fifty-six percent experienced partial response (which is higher than the 
expected $40 \%$ ), 24\% stable disease and 16\% progressive disease. The 12-months PFS rate was $36 \%$ (95\% CI, 0.18-0.54) which is similar to the results seen in CheckMate 214. Authors suggested that SBRT may be useful for immunologically "cold" metastatic lesions [40].

The NIVES study, a phase II multicenter trial evaluated the combination of nivolumab (240 mg every 2 weeks) with SBRT (10 Gy $\times 3$ fractions 7 days after the first infusion of nivolumab) in advanced RCC that progressed on up to two prior systemic therapies [41]. The primary endpoint was not reached with an objective response rate of $17.4 \%$ (for an expected rate of $40 \%$ ). 12-months survival rate was $73.4 \%$. Although such combinations appeared feasible and safe, the median PFS rates were not higher than those reported previously in CheckMate 025 and CheckMate 214 with nivolumab or nivolumab-ipilimumab without SBRT. If the immediate use of RT with ICI remains uncertain, these trials support the idea that RT may be useful in a selected mRCC population made up of patients experiencing dissociated response when one tumor site starts to grow whereas the other sites decrease. It could be used to eradicate ICIs resistant clone.

\subsection{Safety of Combined ICI and Radiation Therapy: Lessons Learned from NSCLC}

In the NSCLC metastatic setting, RT is often used as a palliative treatment. With the emergence of ICI, used alone or as a combination with platinum-based chemotherapy, in front line and latter setting retrospective data related to this combination concurrently with RT have been reported in many case reports and safety appears acceptable [58]. Prospective data related, even scarce, appear reassuring and are summarized below:

\subsubsection{Sequential Schedule}

A secondary analysis of the KEYNOTE-001 phase I trial evaluated the pulmonary toxicity of pembrolizumab after previous radiotherapy for advanced NSCLC patients. Safety profile was acceptable: three $(13 \%)$ patients with previous thoracic radiotherapy developed immune-related pneumonitis compared with one $(1 \%)$ of those without. No toxic death occurred [59].

Phase III clinical trial PACIFIC was also reassuring. Immune-related adverse events (IrAEs) of any grade were reported in $24.2 \%$ of patients in the durvalumab arm and $8.1 \%$ of patients in the placebo group. Grade 3-4 irAEs were respectively reported in $3.4 \%$ and $2.6 \%$ of patients. Grade 3-4 pneumonitis occurred respectively in $3.4 \%$ and $2.6 \%$. No toxic death occurred $[33,34]$.

\subsubsection{Concomitant Schedule}

Safety and tolerability of ICI concurrently with chemoradiotherapy for locally advanced NSCLC were prospectively evaluated in a recent phase I trial. Twenty-one patients received pembrolizumab combined with concurrent chemoradiotherapy (weekly carboplatin and paclitaxel with 60 Gy of radiation in 2 Gy per day). Five cohorts were designed with different doses and administration schedules of pembrolizumab. No dose-limiting toxic effect (defined as grade 4 pneumonitis) was observed in the five cohorts but one patient died of G5 pneumonitis in a safety expansion cohort [31].

Safety analysis of phase II trials DETERRED (chemo-radiotherapy with or without concomitant atezolizumab followed by atezolizumab maintenance) and ETOP-NICOLAS (nivolumab concurrently to chemoradiation followed by nivolumab maintenance) report an acceptable safety profile with no increased toxicity. Reassuringly, for the first 21 enrolled patients, no Grade $\geq 3$ pneumonitis was observed at the end of the 3-months post RT follow-up $[60,61]$.

The underlying pulmonary parenchymal status may favor immune-related pneumonitis, as immune-related pneumonitis is preferentially located within tumor areas involve by tumor and/or radiation fields [62].

A recent PRISMA-compliant systematic review including 51 studies $(n=15,398)$ with $35 \mathrm{ICI}$ alone and $16 \mathrm{ICI}+\mathrm{RT}$ confirmed a comparable grade 3-4 toxicity in using ICI + RT 
(16.3\%, 95\% CI 11.1-22.3\%) compared to ICI alone (22.3\%, 95\% CI 18.1-26.9\%) in CNS melanoma metastases, NSCLC and prostate cancer, regardless of cancer type [63].

\section{Increasing the RT and ICI Synergism: Schedule, ICI Partner and Sequence}

\subsection{Optimizing the Sequence and the Choice of ICI}

Is a combined better than a sequential administration? The optimal schedule actually depends on the type of ICI. The main effect of CTLA4 antibodies seems to be more related to Treg depletion via antibody-dependent cell-mediated cytotoxicity (ADCC) than CD8 ${ }^{+} \mathrm{T}$-cell exhaustion from CTLA4/CD28 axis. Thus, unmodified IgG1 antibodies like ipilimumab (human IgG1/kappa) induce a greater Treg depletion in mouse model than IgG2 antibodies like tremelimumab (human IgG2/kappa) [64,65]. TGFß secretion from preexisting Treg is fundamentally involved in irradiation-induced immunosuppression and inhibits both dendritic cell maturation and CD8 ${ }^{+} \mathrm{T}$-cell cytotoxicity $[15,66]$. Pre-clinical data suggest that prior TGF $B$ inhibition is required to trigger a radiation-induced vaccination [66]. An administration of anti-CTLA4 before RT, in order to deplete preexisting Treg, is a wise choice to reprogram tumoral microenvironment. Young et al. have demonstrated on a murine model of colorectal cancer that anti-CTLA- 4 is more efficient when it is administrated seven days before a single $20 \mathrm{~Gy}$ dose rather than one or seven days after [67]. This concept is also supported by the results of a retrospective study of 29 patients with advanced melanoma. The median overall survival was lower when RT was performed during ipilimumab induction phase compared to after ipilimumab induction phase [68]. Whether in preclinical or clinical settings, anti-CTLA4 and RT association efficacy is hindered by RT-induced PDL1 upregulation [21,42]. By the way, cases of systemic effect of ipilimumab-RT association remains infrequent $[69,70]$. Similarly, in triple negative breast cancer mice model AT-3, Verbubrugge et al. have demonstrated that CD137 and CD40 agonist antibodies associated with RT were an effective regimen to slow tumor growth, but it was unable to cure mice. While the association of anti-PD-1, CD137 agonist and RT was the only combination capable of achieving tumor rejection. In this model, RT induces enrichment of CD137 ${ }^{+} \mathrm{PD}-1^{\text {high }}$ $\mathrm{CD}^{+}$T-cell that recognize AT-3 specific antigen. The efficacy of radioimmunotherapy appears to be highly dependent on the PD-1/PD-L1 axis [71].

The abscopal effect with anti-PD-1/PD-L1 and RT association is more common, but it is often difficult to distinguish a true abscopal effect from a conventional response to anti-PD-1. Most of the clinical trials do not have a control arm and mix ICI-naïve and ICIrefractory patients. Anti-PD-1 has been administered between 0 to 28 days before RT [72,73]. Unlike anti-CTLA-4 or anti-TGFß, the optimal administration schedule of anti-PD-1/PD-L1 and other checkpoints targeting $\mathrm{CD}^{+} \mathrm{T}$-cell (like OX40 agonist) seems to be immediately following radiation therapy [52,74]. This timing corresponds to PD-L1 upregulation with radiation-increasing interferon. What is more, anti-CTLA-4 and anti-PD-1 (or other ICI) do not exhibit redundant effect. In pre-clinical mice model, genetic elimination of PD-L1 on tumor cells or addition of anti-PD-L1 restores response to RT and Ipilimumab association in various xenograft [42]. The clinical toxicity of nivolumab and ipilimumab association is significant. Moreover, sequential approach in order to minimize immune related-adverse events and optimize ipilimumab administration should be considered. Especially because a single dose of ipilimumab has demonstrated partial tumor shrinkage [75].

Many other combinations are possible, either to target multiple immune checkpoints when the doublet is inefficient and to bypass a nonfunctional immune pathway (ex., RT + anti-PD-1 + anti-TIM3 for glioblastoma in murine models) [76]. The association of RT with a CD40 agonist is particularly promising. Indeed, CD40 is a costimulatory protein involves in CD8 ${ }^{+} \mathrm{T}$-cell, $\mathrm{B}$-cell and macrophage activation. CD40 agonist allows activating $\mathrm{CD}^{+}$T-cell without hSTING signaling [71]. Lastly, combinations of RT with other ICI, like anti-LAG3, anti-TIGIT, anti-VISTA, anti-BTLA, are still unexplored.

Several clinical trials are testing the addition of RT to patients who experienced disease progression on prior anti-PD-1. Nevertheless, sequential treatment appears to be less effective than combination $[23,46]$. In our clinical experience, tumoral response 
is uncommon when RT is initiated once the tumor is escaping from ICI therapy. Further trials are ongoing to specify the synergism between miscellaneous ICI and RT combination strategies. Otherwise, these trials used various RT schedules and doses per fraction. In this respect, the extrapolation of results will be challenging.

\subsection{Optimizing the Dose and Regimen of RT}

Balance between radiotherapy-induced pro-inflammatory or anti-inflammatory effect highly depends on the schedule and dose per fraction. Low dose per fraction $(<1 \mathrm{~Gy})$ promotes anti-inflammatory effect whereas high doses ( $>12 \mathrm{~Gy})$ triggers destruction of vasculature and ROS excess, leading to cell death, including immune cells. It also activates TREX1 exonuclease that degrades cytosolic double-stranded DNA and consequently downregulate hSTING [8]. On the other hand, higher doses mean stronger MHC-I upregulation [19].

Dewan et al. has determined that hypofractionated radioimmunotherapy with ipilimumab is superior to a single fraction [77]. Contrary to Lugade et al. that reported a significant greater inhibition of tumor growth in B16 mouse melanoma model [78]. On second thoughts, hypofractionated radiotherapy is less cytotoxic on radio-resistant tumors but it generates better adjuvanticity [77].

Schaue et al. have proposed an hypofractionated regimen with two fractions of $7.5 \mathrm{~Gy}$ for best ratio cross-priming/Treg cell increase, but the optimized dose remains model dependent [79]. Indeed recently, Qin Q et al. and Quéro et al. have reported respectively 3 and 4 patients suffering from heavily pretreated and anti-PD-1-naïve Hodgkin lymphoma whom all underwent durable and complete response (CR) with association of palliative normofractioned RT and anti-PD-1 (the historical CR rate is estimated at 20\%) [80,81]. Both conventional radiotherapy and stereotactic ablative radiotherapy (SARB) are capable of inducing an immune response [82]. Similarly, a low dose radiotherapy has been tested to recover CAR-T cell efficacy. Herein, a single dose of 2 Gy successfully increases sensitivity of antigen-negative tumor cells to death-receptor engagement. Thereby, even in the absence of CAR/antigen interaction, CAR-T cells induce antigen-negative tumor cell apoptosis through the extrinsic pathway with the TNF-related apoptosis-inducing ligand (TRAIL) engagement [83]. At last, low dose radiotherapy improve T-cell receptor independent cytotoxicity.

Regardless of this, a large number of preclinical and clinical studies have evaluated dose per fraction between 0.5 to $30 \mathrm{~Gy}$ ranging from 1 to 30 fractions, sometimes with contradictory results $[73,84]$.

\subsection{Optimize the Irradiation Field}

As previously described, the abscopal effect requires effective T cell functions. Lymphopenia is known to negatively affect outcomes in cancer patients [85]. Radiotherapy techniques and dosimetry affect the absolute lymphocyte count (ALC) and thus may impair the desired abscopal effect. Chen et al. recently reported the analysis of 3 phase I/II trials focusing on the putative relation between ALC and abscopal response. In these trials, all 153 patients underwent combined immunotherapy and RT, in metastatic setting. The post-RT absolute lymphocyte count, as a continuous variable, positively correlated with abscopal response: $34.2 \%$ of abscopal response with ALC higher than the median value vs. $3.9 \%$ with ALC lower than the median value $p<0.001)$. Similar results were reported for pre-RT ALC (30.3\% vs. $7.8 \%$ respectively, $p<0.001)$. In Cox multivariate analysis, a lower post-RT ALC was associated with poorer PFS $(p=0.009)$ and OS $(p=0.026)$ [86]. Marciscano et al. reported that irradiation of the draining lymph nodes impairs adaptive immune response mainly through chemokines expression and CD8 ${ }^{+} \mathrm{T}$ cell trafficking and thus may be deleterious when combined with immunotherapy [87]. Considering these observations, lymph nodes sparing radiotherapy appears as an interesting strategy to preserve lymphocytes count and function and thus to synergize with immunotherapy. 


\subsection{Combination of Radiotherapy and Other Immunotherapeutic Agents}

Many biological therapeutics including cytokines, vaccines, TLR agonists or innovative immune checkpoint inhibitors have been evaluated in combination with radiotherapy to improve the abscopal response. Among these therapeutics, we will focus on cytokines GM-CSF, IL2, anti TGF $\beta$.

\subsubsection{GM-CSF (Granulocyte-Macrophage Colony-Stimulating Factor)}

The cytokine GM-CSF acts as an immunoadjuvant by promoting the proliferation, the maturation and the migration of the dendritic cells, improving the presentation of Tumor Associated Antigens (TAAs) and thus generating an efficient T-cell response. In 2015, a proof-of-principle trial, led by Golden et al. evaluated a concurrent radiotherapy (35 Gy in 10 fractions) to one metastatic site and GM-CSF injected daily for 2 weeks (starting during the second week of radiotherapy) in patients with solid tumors receiving chemotherapy or hormone therapy. The primary objective was the rate of abscopal response. Among the 41 enrolled patients, abscopal response occurred in 11 patients. Toxicity profile was manageable and no Grade 5 adverse event occurred [88]. Liu et al. recently described similar results [89]. They evaluated abscopal effect of local radiotherapy and GM-CSF injection in patients with metastatic thoracic cancers, including lung cancers, thymic cancer, esophageal cancer, tracheal adenoid cystic carcinoma and pleural mesothelioma. On the 30 enrolled patients, 4 experienced abscopal effect ( 2 lung cancers and 2 thymic cancers) and 19 experienced stable disease. Combination of GM-CSF and radiotherapy appeared as a promising combination to improve abscopal effect. A phase II led by Kwek et al. evaluated the association of GM-CSF and ipilimumab in metastatic melanoma. Twentytwo patients received induction treatment with ipilimumab $10 \mathrm{mg} / \mathrm{kg}$ every 3 weeks for four doses in combination with GM-CSF $125 \mu \mathrm{g} / \mathrm{m}^{2}$ for 14 days beginning on the day of the ipilimumab infusion and then consolidation treatment with GM-CSF on the same schedule for 3 months without ipilimumab. The overall response rate was $32 \%$, the median PFS was 3.5 months and the median OS was 21.1 months, suggesting that the combination may be more effective than ipilimumab monotherapy [90].

The ongoing study NCT02648282 is evaluating the association between anti PD-1 pembrolizumab, cyclophosphamide, SBRT and GVAX in patients with locally advanced pancreatic cancer. GVAX is a pancreatic cancer vaccine made of tumor cells genetically modified to release the immuno-adjuvant cytokine GM-CSF. Primary and secondary objectives are the distant metastasis-free survival and the toxicity profile. Results are warranted.

\subsubsection{Interleukin-2 (IL2)}

Combination of RT and interleukins have been studied for a long time. A pilot study led by Seung et al. evaluated SBRT followed by high-dose of IL-2 in metastatic melanoma or renal cell carcinoma patients. Patients received 1, 2 or 3 doses of SBRT (20 Gy per fraction) followed by IL-2 $(600,000 \mathrm{IU} / \mathrm{kg})$ every $8 \mathrm{~h}$ for a maximum of 14 doses. Eight of the twelve enrolled patients achieved a complete or partial response ( $1 \mathrm{Cr}$ and $7 \mathrm{PR}$ ), mostly melanoma patients [91].

\subsubsection{Anti-TGFß}

Radiotherapy is known to increase TGFß activation in the irradiated tissue and to promote immunosuppressive effects, by downregulating T-cells activation and by promoting regulatory T cells and myeloid derived suppressors cells' activation [92,93]. RodriguezRuiz et al. previously demonstrated that the combination of radiotherapy with both anti PD1 and anti-CD137 was associated with favorable effects on distant nonirradiated lesions in murine models transplanted with colorectal, melanoma or breast cancer cells [6]. In 2019, using syngeneic bilateral tumor models in which only one lesion receive radiotherapy, they demonstrated that TGFß blockade enhances radiotherapy abscopal effects in combination with anti-PD-1 and anti-CD137 immunostimulatory monoclonal antibodies. The reduction of nonirradiated tumor volume was significantly higher in the RT/anti PD-1/anti- 
CD137/anti-TGFß group versus the RT/anti-PD-1/anti-CD137 group. This combined treatment was associated with an increase in CD8 T cells infiltrating non-irradiated lesions and with an increased Granzyme-B expression and thus putative cytotoxic effects [94].

All of the optimization described above are summarized in Figure 2.

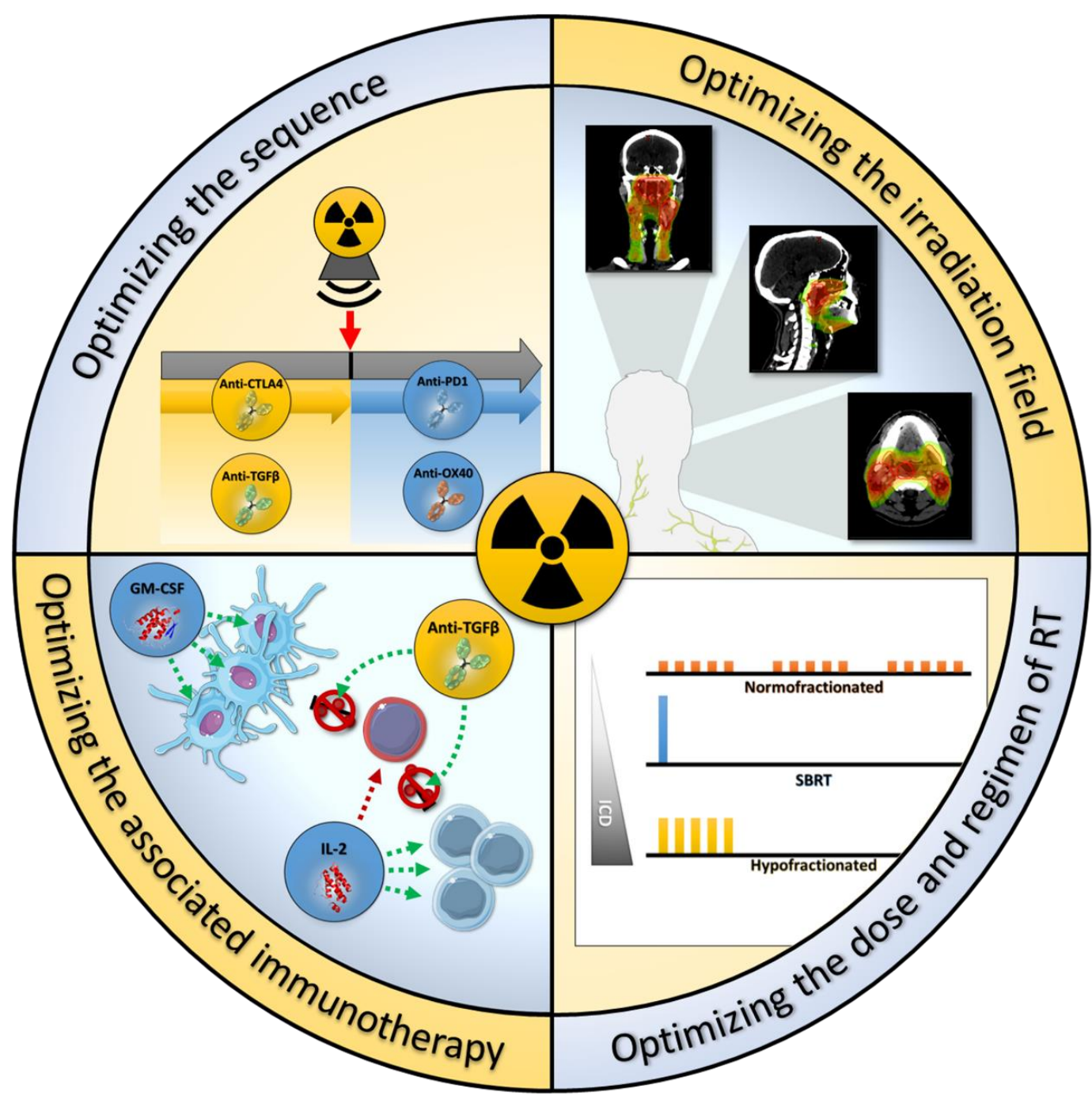

Figure 2. The different possible optimizations of RT to improve its immune effects. The optimisation of RT immune effects could be summarized in four categories: (i) optimizing the sequence, (ii) optimizing the associated immunotherapy, (iii) optimizing the dose per fraction and RT regimen, (iv) optimizing the irradition field. CTLA4, cytotoxic T-lymphocyteassociated protein 4; GM-CSF, granulocyte-macrophage colony-stimulating factor; IL-2, interleukin 2; PD1, programmed cell death protein 1; SBRT, stereotaxique body radiation therapy; TGF $\beta$, transforming growth factor beta. This figure was created using Servier Medical Art templates (Creative Common Attribution 3.0), https:/ / smart.servier.com (access on 29 December 2020).

\section{Conclusions}

ICD is a regulated death able to elicit a specific immune response through the release of DAMPs from the dying cells. Radiation therapy is a well-known ICD inducer which may be responsible for the theoretical abscopal effect. This off-target effect is a reality in pre-clinical models but is more difficult to prove in the clinic. The emergence of ICI, a new class of immunotherapeutic agents able to release the brake on the adaptive anti-tumor immune response brings new interest in exploiting radiation-induced ICD. There is a strong biological rationale to support a synergy between RT and ICI. First clinical results for combined RT-ICI are emerging: most of them are retrospective or non-randomized 
phase II trials and difficult to interpret. However, these data suggest that this combination is safe with no clear increase in ICI-induced toxicity with RT. First large, randomized trials evaluating RT-ICI combination are currently ongoing and first results are awaited.

We have already some data from sequential treatment with chemo-radiotherapy followed by ICI such as the PACIFIC trial with clear positive results. Nevertheless, sequential trials raise the question of a true synergistic effect between RT and ICI and an "opportunistic" effect which means that patients who tolerate well chemoradiotherapy and show no progression at the end would be the most likely to benefit from ICI "maintenance". In the latter case, we are not evaluating the RT-ICI synergy.

Fifty percent of cancer patients will benefit from radiotherapy. The RT-ICI association is safe, it integrates quite easily into daily practice, and it can be performed in weakened patients at an acceptable clinical cost. Compared to the targeted therapy-ICI association, adverse events and costs are lower. Similarly, the chemotherapy-ICI association is still less tolerated. The CAR-T cell and ICI association is promising. However, this strategy still presents many limitations: the choice of membrane cell targets is restricted, it involves complicated logistics, its price is prohibitive, and it has a worse toxicity profile (like cytokine release syndrome or CAR-T cell-related encephalopathy syndrome) [95]. The main limit to RT-ICI association democratization remains its inconsistent efficiency and the youthfulness of the radioimmunology science.

As seen in pre-clinical studies, schedule, dose, fractionation or ICI partner could impact the combination efficacy [4]. Many open questions will remain about how to optimize RT-ICI synergy. We will need to perform randomized trials with dedicated endpoints to unlock the full potential of radiation-induced ICD combined with ICI-restored immune response.

Author Contributions: Conceptualization, Y.-A.V.; writing—original draft preparation, A.P. and A.S. (these authors contributed equally to this work); writing-review and editing, J.-E.B. and Y.-A.V.; visualization, A.P.; supervision, S.O. and Y.-A.V.; project administration, Y.-A.V. All authors have read and agreed to the published version of the manuscript.

Funding: This research received no external funding.

Data Availability Statement: Not applicable.

Conflicts of Interest: Y.V. received honoraria for advisory board from the following companies: BMS, IPSEN, MSD, Pfizer, Novartis, Sanofi, Astellas, Janssen. Other authors declare no conflict of interest.

$\begin{array}{ll}\text { Abbreviations } \\ \text { ALC } & \text { Absolute Lymphocyte Count } \\ \text { APC } & \text { Antigen-Presenting Cell } \\ \text { ATP } & \text { Adenosine Triphosphate } \\ \text { BTLA } & \text { B and T Lymphocyte Attenuator } \\ \text { CALR } & \text { Calreticulin } \\ \text { CAR } & \text { Chimeric Antigen Receptor } \\ \text { CTLA4 } & \text { Cytotoxic T-Lymphocyte-Associated Protein } \\ \text { CRT } & \text { Chemoradiotherapy } \\ \text { DAMPs } & \text { Damage-Associated Molecular Patterns } \\ \text { DC } & \text { Dendritic Cell } \\ \text { HMGB1 } & \text { High Mobility Group Box 1 } \\ \text { HNSCC } & \text { Head and Neck Squamous Cell Carcinoma } \\ \text { HSP70/90 } & \text { Heat Shock Proteins 70/90 } \\ \text { ICD } & \text { Immunogenic Cell Death } \\ \text { ICI } & \text { Immune Checkpoint Inhibitor } \\ \text { irAEs } & \text { Immune-related Adverse Events } \\ \text { LA } & \text { Locally Advanced } \\ \text { LAG3 } & \text { Lymphocyte Activation Gene 3 } \\ \text { MDSC } & \text { Myeloid-Derived Suppressor Cell } \\ \text { MHC-1 } & \text { Major Histocompatibility Complex class 1 }\end{array}$




$\begin{array}{ll}\text { NSCLC } & \text { Non-Small Cell Lung Carcinoma } \\ \text { OS } & \text { Overall Survival } \\ \text { PD-1 } & \text { Programmed cell death 1 } \\ \text { PD-L1 } & \text { Programmed death-ligand 1 } \\ \text { ROS } & \text { Reactive Oxygen Species } \\ \text { PFS } & \text { Progression Free Survival } \\ \text { RCC } & \text { Renal Cell Carcinoma } \\ \text { RT } & \text { Radiation Therapy } \\ \text { SBRT } & \text { Stereotactic Body Radiation Therapy } \\ \text { TGF } \beta & \text { Transforming Growth Factor Beta } \\ \text { TIGIT } & \text { T cell Immunoglobulin and ITIM domain } \\ \text { TNF } \alpha & \text { Tumor Necrosis Factor Alpha } \\ \text { Treg } & \text { Regulatory T cells } \\ \text { TREX1 } & \text { Three prime Repair Exonuclease 1 } \\ \text { TRAIL } & \text { TNF-related Apoptosis-Inducing Ligand } \\ \text { VISTA } & \text { V-Domain Ig Suppressor of T cell Activation }\end{array}$

\section{References}

1. Dagenais, G.R.; Leong, D.P.; Rangarajan, S.; Lanas, F.; Lopez-Jaramillo, P.; Gupta, R.; Diaz, R.; Avezum, A.; Oliveira, G.B.F.; Wielgosz, A.; et al. Variations in Common Diseases, Hospital Admissions, and Deaths in Middle-Aged Adults in 21 Countries from Five Continents (PURE): A Prospective Cohort Study. Lancet 2020, 395, 785-794. [CrossRef]

2. Pitt, J.M.; Vétizou, M.; Daillère, R.; Roberti, M.P.; Yamazaki, T.; Routy, B.; Lepage, P.; Boneca, I.G.; Chamaillard, M.; Kroemer, G.; et al. Resistance Mechanisms to Immune-Checkpoint Blockade in Cancer: Tumor-Intrinsic and -Extrinsic Factors. Immunity 2016, 44, 1255-1269. [CrossRef] [PubMed]

3. Mole, R.H. Whole Body Irradiation-Radiobiology or Medicine? Br. J. Radiol. 1953, 26, 234-241. [CrossRef]

4. Marconi, R.; Strolin, S.; Bossi, G.; Strigari, L. A Meta-Analysis of the Abscopal Effect in Preclinical Models: Is the Biologically Effective Dose a Relevant Physical Trigger? PLoS ONE 2017, 12, e0171559. [CrossRef] [PubMed]

5. Demaria, S.; Ng, B.; Devitt, M.L.; Babb, J.S.; Kawashima, N.; Liebes, L.; Formenti, S.C. Ionizing Radiation Inhibition of Distant Untreated Tumors (Abscopal Effect) Is Immune Mediated. Int. J. Radiat. Oncol. 2004, 58, 862-870. [CrossRef]

6. $\quad$ Rodriguez-Ruiz, M.E.; Rodriguez, I.; Garasa, S.; Barbes, B.; Solorzano, J.L.; Perez-Gracia, J.L.; Labiano, S.; Sanmamed, M.F.; Azpilikueta, A.; Bolaños, E.; et al. Abscopal Effects of Radiotherapy Are Enhanced by Combined Immunostimulatory MAbs and Are Dependent on CD8 T Cells and Crosspriming. Cancer Res. 2016, 76, 5994-6005. [CrossRef]

7. Galluzzi, L.; Vitale, I.; Warren, S.; Adjemian, S.; Agostinis, P.; Martinez, A.B.; Chan, T.A.; Coukos, G.; Demaria, S.; Deutsch, E.; et al. Consensus Guidelines for the Definition, Detection and Interpretation of Immunogenic Cell Death. J. Immunother. Cancer 2020, 8. [CrossRef]

8. Vanpouille-Box, C.; Alard, A.; Aryankalayil, M.J.; Sarfraz, Y.; Diamond, J.M.; Schneider, R.J.; Inghirami, G.; Coleman, C.N.; Formenti, S.C.; Demaria, S. DNA Exonuclease Trex1 Regulates Radiotherapy-Induced Tumour Immunogenicity. Nat. Commun. 2017, 8, 15618. [CrossRef]

9. Galluzzi, L.; Vitale, I.; Aaronson, S.A.; Abrams, J.M.; Adam, D.; Agostinis, P.; Alnemri, E.S.; Altucci, L.; Amelio, I.; Andrews, D.W.; et al. Molecular Mechanisms of Cell Death: Recommendations of the Nomenclature Committee on Cell Death 2018. Cell Death Differ. 2018, 25, 486-541. [CrossRef]

10. Tang, D.; Kang, R.; Berghe, T.V.; Vandenabeele, P.; Kroemer, G. The Molecular Machinery of Regulated Cell Death. Cell Res. 2019, 29, 347-364. [CrossRef] [PubMed]

11. Zhou, J.; Wang, G.; Chen, Y.; Wang, H.; Hua, Y.; Cai, Z. Immunogenic Cell Death in Cancer Therapy: Present and Emerging Inducers. J. Cell. Mol. Med. 2019, 23, 4854-4865. [CrossRef] [PubMed]

12. Apetoh, L.; Ghiringhelli, F.; Tesniere, A.; Obeid, M.; Ortiz, C.; Criollo, A.; Mignot, G.; Maiuri, M.C.; Ullrich, E.; Saulnier, P.; et al. Toll-like Receptor 4-Dependent Contribution of the Immune System to Anticancer Chemotherapy and Radiotherapy. Nat. Med. 2007, 13, 1050-1059. [CrossRef] [PubMed]

13. Kroemer, G.; Galluzzi, L.; Kepp, O.; Zitvogel, L. Immunogenic Cell Death in Cancer Therapy. Annu. Rev. Immunol. 2013, 31, 51-72. [CrossRef]

14. Jiang, W.; Chan, C.K.; Weissman, I.L.; Kim, B.Y.S.; Hahn, S.M. Immune Priming of the Tumor Microenvironment by Radiation. Trends Cancer 2016, 2, 638-645. [CrossRef]

15. Kobie, J.J.; Wu, R.S.; Kurt, R.A.; Lou, S.; Adelman, M.K.; Whitesell, L.J.; Ramanathapuram, L.V.; Arteaga, C.L.; Akporiaye, E.T. Transforming Growth Factor Beta Inhibits the Antigen-Presenting Functions and Antitumor Activity of Dendritic Cell Vaccines. Cancer Res. 2003, 63, 1860-1864. [PubMed]

16. Zhao, X.; Shao, C. Radiotherapy-Mediated Immunomodulation and Anti-Tumor Abscopal Effect Combining Immune Checkpoint Blockade. Cancers 2020, 12, 2762. [CrossRef]

17. Weichselbaum, R.R.; Liang, H.; Deng, L.; Fu, Y.-X. Radiotherapy and Immunotherapy: A Beneficial Liaison? Nat. Rev. Clin. Oncol. 2017, 14, 365-379. [CrossRef] 
18. Deng, L.; Liang, H.; Xu, M.; Yang, X.; Burnette, B.; Arina, A.; Li, X.-D.; Mauceri, H.; Beckett, M.; Darga, T.; et al. STING-Dependent Cytosolic DNA Sensing Promotes Radiation-Induced Type I Interferon-Dependent Antitumor Immunity in Immunogenic Tumors. Immunity 2014, 41, 843-852. [CrossRef]

19. Reits, E.A.; Hodge, J.W.; Herberts, C.A.; Groothuis, T.A.; Chakraborty, M.; Wansley, E.K.; Camphausen, K.; Luiten, R.M.; de Ru, A.H.; Neijssen, J.; et al. Radiation Modulates the Peptide Repertoire, Enhances MHC Class I Expression, and Induces Successful Antitumor Immunotherapy. J. Exp. Med. 2006, 203, 1259-1271. [CrossRef]

20. Ganss, R.; Ryschich, E.; Klar, E.; Arnold, B.; Hämmerling, G.J. Combination of T-Cell Therapy and Trigger of Inflammation Induces Remodeling of the Vasculature and Tumor Eradication. Cancer Res. 2002, 62, 1462-1470.

21. Deng, L.; Liang, H.; Burnette, B.; Beckett, M.; Darga, T.; Weichselbaum, R.R.; Fu, Y.-X. Irradiation and Anti-PD-L1 Treatment Synergistically Promote Antitumor Immunity in Mice. J. Clin. Investig. 2014, 124, 687-695. [CrossRef] [PubMed]

22. Kachikwu, E.L.; Iwamoto, K.S.; Liao, Y.-P.; DeMarco, J.J.; Agazaryan, N.; Economou, J.S.; McBride, W.H.; Schaue, D. Radiation Enhances Regulatory T Cell Representation. Int. J. Radiat. Oncol. 2011, 81, 1128-1135. [CrossRef]

23. Dovedi, S.J.; Illidge, T.M. The Antitumor Immune Response Generated by Fractionated Radiation Therapy May Be Limited by Tumor Cell Adaptive Resistance and Can Be Circumvented by PD-L1 Blockade. Oncoimmunology 2015, 4, e1016709. [CrossRef] [PubMed]

24. Roux, C.; Jafari, S.M.; Shinde, R.; Duncan, G.; Cescon, D.W.; Silvester, J.; Chu, M.F.; Hodgson, K.; Berger, T.; Wakeham, A.; et al. Reactive Oxygen Species Modulate Macrophage Immunosuppressive Phenotype through the Up-Regulation of PD-L1. Proc. Natl. Acad. Sci. USA 2019, 116, 4326-4335. [CrossRef] [PubMed]

25. Jobling, M.F.; Mott, J.D.; Finnegan, M.T.; Jurukovski, V.; Erickson, A.C.; Walian, P.J.; Taylor, S.E.; Ledbetter, S.; Lawrence, C.M.; Rifkin, D.B.; et al. Isoform-Specific Activation of Latent Transforming Growth Factor $\beta$ (LTGF- $\beta$ ) by Reactive Oxygen Species. Radiat. Res. 2006, 166, 839-848. [CrossRef] [PubMed]

26. Park, S.S.; Dong, H.; Liu, X.; Harrington, S.M.; Krco, C.J.; Grams, M.P.; Mansfield, A.S.; Furutani, K.M.; Olivier, K.R.; Kwon, E.D. PD-1 Restrains Radiotherapy-Induced Abscopal Effect. Cancer Immunol. Res. 2015, 3, 610-619. [CrossRef]

27. Skinner, H.D.; Giri, U.; Yang, L.P.; Kumar, M.; Liu, Y.; Story, M.D.; Pickering, C.R.; Byers, L.A.; Williams, M.D.; Wang, J.; et al. Integrative Analysis Identifies a Novel AXL-PI3 Kinase-PD-L1 Signaling Axis Associated with Radiation Resistance in Head and Neck Cancer. Clin. Cancer Res. 2017, 23, 2713-2722. [CrossRef]

28. Formenti, S.C.; Demaria, S. Combining Radiotherapy and Cancer Immunotherapy: A Paradigm Shift. JNCI J. Natl. Cancer Inst. 2013, 105, 256-265. [CrossRef] [PubMed]

29. Kalbasi, A.; June, C.H.; Haas, N.; Vapiwala, N. Radiation and Immunotherapy: A Synergistic Combination. J. Clin. Investig. 2013, 123, 2756-2763. [CrossRef]

30. Demaria, S.; Formenti, S.C. Radiation as an Immunological Adjuvant: Current Evidence on Dose and Fractionation. Front. Oncol. 2012, 2. [CrossRef]

31. Jabbour, S.K.; Berman, A.T.; Decker, R.H.; Lin, Y.; Feigenberg, S.J.; Gettinger, S.N.; Aggarwal, C.; Langer, C.J.; Simone, C.B.; Bradley, J.D.; et al. Phase 1 Trial of Pembrolizumab Administered Concurrently With Chemoradiotherapy for Locally Advanced Non-Small Cell Lung Cancer: A Nonrandomized Controlled Trial. JAMA Oncol. 2020, 6, 848. [CrossRef] [PubMed]

32. Gray, J.E.; Villegas, A.; Daniel, D.; Vicente, D.; Murakami, S.; Hui, R.; Kurata, T.; Chiappori, A.; Lee, K.H.; Cho, B.C.; et al. Three-Year Overall Survival with Durvalumab after Chemoradiotherapy in Stage III NSCLC-Update from PACIFIC. J. Thorac. Oncol. 2020, 15, 288-293. [CrossRef]

33. Antonia, S.J.; Villegas, A.; Daniel, D.; Vicente, D.; Murakami, S.; Hui, R.; Yokoi, T.; Chiappori, A.; Lee, K.H.; de Wit, M.; et al. Durvalumab after Chemoradiotherapy in Stage III Non-Small-Cell Lung Cancer. N. Engl. J. Med. 2017, 377, 1919-1929. [CrossRef] [PubMed]

34. Antonia, S.J.; Villegas, A.; Daniel, D.; Vicente, D.; Murakami, S.; Hui, R.; Kurata, T.; Chiappori, A.; Lee, K.H.; de Wit, M.; et al. Overall Survival with Durvalumab after Chemoradiotherapy in Stage III NSCLC. N. Engl. J. Med. 2018, 379, 2342-2350. [CrossRef] [PubMed]

35. Durm, G.A.; Jabbour, S.K.; Althouse, S.K.; Liu, Z.; Sadiq, A.A.; Zon, R.T.; Jalal, S.I.; Kloecker, G.H.; Williamson, M.J.; Reckamp, K.L.; et al. A Phase 2 Trial of Consolidation Pembrolizumab Following Concurrent Chemoradiation for Patients with Unresectable Stage III Non-Small Cell Lung Cancer: Hoosier Cancer Research Network LUN 14-179. Cancer 2020, 126, 4353-4361. [CrossRef]

36. Bauml, J.M.; Mick, R.; Ciunci, C.; Aggarwal, C.; Davis, C.; Evans, T.; Deshpande, C.; Miller, L.; Patel, P.; Alley, E.; et al. Pembrolizumab After Completion of Locally Ablative Therapy for Oligometastatic Non-Small Cell Lung Cancer: A Phase 2 Trial. JAMA Oncol. 2019, 5, 1283. [CrossRef]

37. Powell, S.F.; Gold, K.A.; Gitau, M.M.; Sumey, C.J.; Lohr, M.M.; McGraw, S.C.; Nowak, R.K.; Jensen, A.W.; Blanchard, M.J.; Fischer, C.D.; et al. Safety and Efficacy of Pembrolizumab With Chemoradiotherapy in Locally Advanced Head and Neck Squamous Cell Carcinoma: A Phase IB Study. J. Clin. Oncol. 2020, 38, 2427-2437. [CrossRef]

38. Cohen, E.E.; Ferris, R.L.; Psyrri, A.; Haddad, R.; Tahara, M.; Bourhis, J.; Harrington, K.J.; Chang, P.M.-H.; Lin, J.-C.; Razaq, M.; et al. 910 O Primary Results of the Phase III JAVELIN Head \& Neck 100 Trial: Avelumab plus Chemoradiotherapy (CRT) Followed by Avelumab Maintenance vs CRT in Patients with Locally Advanced Squamous Cell Carcinoma of the Head and Neck (LA SCCHN). Ann. Oncol. 2020, 31, S658. [CrossRef] 
39. Bourhis, J.; Sire, C.; Tao, Y.; Martin, L.; Alfonsi, M.; Prevost, J.B.; Rives, M.; Lafond, C.; Tourani, J.M.; Biau, J.; et al. LBA38 Pembrolizumab versus Cetuximab, Concomitant with Radiotherapy (RT) in Locally Advanced Head and Neck Squamous Cell Carcinoma (LA-HNSCC): Results of the GORTEC 2015-01 “PembroRad" Randomized Trial. Ann. Oncol. 2020, 31 , S1168. [CrossRef]

40. Hammers, H.J.; Vonmerveldt, D.; Ahn, C.; Nadal, R.M.; Drake, C.G.; Folkert, M.R.; Laine, A.M.; Courtney, K.D.; Brugarolas, J.; Song, D.Y.; et al. Combination of Dual Immune Checkpoint Inhibition (ICI) with Stereotactic Radiation (SBRT) in Metastatic Renal Cell Carcinoma (MRCC) (RADVAX RCC). J. Clin. Oncol. 2020, 38, 614. [CrossRef]

41. Masini, C.; Iotti, C.; De Giorgi, U.; Bellia, R.S.; Buti, S.; Salaroli, F.; Zampiva, I.; Mazzarotto, R.; Mucciarini, C.; Baldessari, C.; et al. Nivolumab (NIVO) in Combination with Stereotactic Body Radiotherapy (SBRT) in Pretreated Patients (Pts) with Metastatic Renal Cell Carcinoma (MRCC): First Results of Phase II NIVES Study. J. Clin. Oncol. 2020, 38, 613. [CrossRef]

42. Twyman-Saint Victor, C.; Rech, A.J.; Maity, A.; Rengan, R.; Pauken, K.E.; Stelekati, E.; Benci, J.L.; Xu, B.; Dada, H.; Odorizzi, P.M.; et al. Radiation and Dual Checkpoint Blockade Activate Non-Redundant Immune Mechanisms in Cancer. Nature 2015, 520, 373-377. [CrossRef]

43. Hiniker, S.M.; Reddy, S.A.; Maecker, H.T.; Subrahmanyam, P.B.; Rosenberg-Hasson, Y.; Swetter, S.M.; Saha, S.; Shura, L.; Knox, S.J A Prospective Clinical Trial Combining Radiation Therapy With Systemic Immunotherapy in Metastatic Melanoma. Int. J. Radiat. Oncol. 2016, 96, 578-588. [CrossRef]

44. Postow, M.A.; Knox, S.J.; Goldman, D.A.; Elhanati, Y.; Mavinkurve, V.; Wong, P.; Halpenny, D.; Reddy, S.K.; Vado, K.; McCabe, D.; et al. A Prospective, Phase 1 Trial of Nivolumab, Ipilimumab, and Radiotherapy in Patients with Advanced Melanoma. Clin. Cancer Res. 2020, 26, 3193-3201. [CrossRef] [PubMed]

45. Yang, H.; Jin, T.; Li, M.; Xue, J.; Lu, B. Synergistic Effect of Immunotherapy and Radiotherapy in Non-Small Cell Lung Cancer: Current Clinical Trials and Prospective Challenges. Precis. Clin. Med. 2019, 2, 57-70. [CrossRef]

46. Dovedi, S.J.; Adlard, A.L.; Lipowska-Bhalla, G.; McKenna, C.; Jones, S.; Cheadle, E.J.; Stratford, I.J.; Poon, E.; Morrow, M.; Stewart, R.; et al. Acquired Resistance to Fractionated Radiotherapy Can Be Overcome by Concurrent PD-L1 Blockade. Cancer Res. 2014, 74, 5458-5468. [CrossRef] [PubMed]

47. Spaas, M.; Lievens, Y. Is the Combination of Immunotherapy and Radiotherapy in Non-Small Cell Lung Cancer a Feasible and Effective Approach? Front. Med. 2019, 6, 244. [CrossRef]

48. Knisely, J.P.S.; Yu, J.B.; Flanigan, J.; Sznol, M.; Kluger, H.M.; Chiang, V.L.S. Radiosurgery for Melanoma Brain Metastases in the Ipilimumab Era and the Possibility of Longer Survival: Clinical Article. J. Neurosurg. 2012, 117, 227-233. [CrossRef] [PubMed]

49. Kiess, A.P.; Wolchok, J.D.; Barker, C.A.; Postow, M.A.; Tabar, V.; Huse, J.T.; Chan, T.A.; Yamada, Y.; Beal, K. Stereotactic Radiosurgery for Melanoma Brain Metastases in Patients Receiving Ipilimumab: Safety Profile and Efficacy of Combined Treatment. Int. J. Radiat. Oncol. 2015, 92, 368-375. [CrossRef]

50. Kabiljo, J.; Harpain, F.; Carotta, S.; Bergmann, M. Radiotherapy as a Backbone for Novel Concepts in Cancer Immunotherapy. Cancers 2019, 12, 79. [CrossRef]

51. Stokes, W.A.; Binder, D.C.; Jones, B.L.; Oweida, A.J.; Liu, A.K.; Rusthoven, C.G.; Karam, S.D. Impact of Immunotherapy among Patients with Melanoma Brain Metastases Managed with Radiotherapy. J. Neuroimmunol. 2017, 313, 118-122. [CrossRef] [PubMed]

52. Qian, J.M.; Yu, J.B.; Kluger, H.M.; Chiang, V.L.S. Timing and Type of Immune Checkpoint Therapy Affect the Early Radiographic Response of Melanoma Brain Metastases to Stereotactic Radiosurgery: Immunotherapy and SRS in Brain Metastases. Cancer 2016, 122, 3051-3058. [CrossRef]

53. Ahmed, K.A.; Stallworth, D.G.; Kim, Y.; Johnstone, P.A.S.; Harrison, L.B.; Caudell, J.J.; Yu, H.H.M.; Etame, A.B.; Weber, J.S.; Gibney, G.T. Clinical Outcomes of Melanoma Brain Metastases Treated with Stereotactic Radiation and Anti-PD-1 Therapy. Ann. Oncol. 2016, 27, 434-441. [CrossRef]

54. Komatsu, T.; Konishi, K.; Aoshima, M.; Tokura, Y.; Nakamura, K. Combined Radiotherapy with Nivolumab for Extracranial Metastatic Malignant Melanoma. Jpn. J. Radiol. 2018, 36, 712-718. [CrossRef]

55. Nardin, C.; Mateus, C.; Texier, M.; Lanoy, E.; Hibat-Allah, S.; Ammari, S.; Robert, C.; Dhermain, F. Tolerance and Outcomes of Stereotactic Radiosurgery Combined with Anti-Programmed Cell Death-1 (Pembrolizumab) for Melanoma Brain Metastases. Melanoma Res. 2018, 28, 111-119. [CrossRef] [PubMed]

56. Aboudaram, A.; Modesto, A.; Chaltiel, L.; Gomez-Roca, C.; Boulinguez, S.; Sibaud, V.; Delord, J.-P.; Chira, C.; Delannes, M.; Moyal, E.; et al. Concurrent Radiotherapy for Patients with Metastatic Melanoma and Receiving Anti-Programmed-Death 1 Therapy: A Safe and Effective Combination. Melanoma Res. 2017, 27, 485-491. [CrossRef] [PubMed]

57. Miyauchi, S.; Kim, S.S.; Pang, J.; Gold, K.A.; Gutkind, J.S.; Califano, J.A.; Mell, L.K.; Cohen, E.E.W.; Sharabi, A.B. Immune Modulation of Head and Neck Squamous Cell Carcinoma and the Tumor Microenvironment by Conventional Therapeutics. Clin. Cancer Res. 2019, 25, 4211-4223. [CrossRef] [PubMed]

58. Ettinger, D.S.; Wood, D.E.; Aggarwal, C.; Aisner, D.L.; Akerley, W.; Bauman, J.R.; Bharat, A.; Bruno, D.S.; Chang, J.Y.; Chirieac, L.R.; et al. NCCN Guidelines Insights: Non-Small Cell Lung Cancer, Version 1.2020. J. Natl. Compr. Canc. Netw. 2019, 17, 1464-1472. [CrossRef]

59. Shaverdian, N.; Lisberg, A.E.; Bornazyan, K.; Veruttipong, D.; Goldman, J.W.; Formenti, S.C.; Garon, E.B.; Lee, P. Previous Radiotherapy and the Clinical Activity and Toxicity of Pembrolizumab in the Treatment of Non-Small-Cell Lung Cancer: A Secondary Analysis of the KEYNOTE-001 Phase 1 Trial. Lancet Oncol. 2017, 18, 895-903. [CrossRef] 
60. Peters, S.; Felip, E.; Dafni, U.; Tufman, A.; Guckenberger, M.; Irigoyen, A.; Nadal, E.; Becker, A.; Vees, H.; Pless, M.; et al. Efficacy Evaluation of Concurrent Nivolumab Addition to a First-Line, Concurrent Chemo-Radiotherapy Regimen in Unresectable Locally Advanced NSCLC: Results from the European Thoracic Oncology Platform (ETOP 6-14) NICOLAS Phase II Trial. Ann. Oncol. 2019, 30, v591. [CrossRef]

61. Lin, S.; Lin, X.; Clay, D.; Yao, L.; Mok, I.; Gomez, D.; Kurie, J.; Simon, G.; Blumenschein, G.; Young, J.; et al. OA01.06 DETERRED: Phase II Trial Combining Atezolizumab Concurrently with Chemoradiation Therapy in Locally Advanced Non-Small Cell Lung Cancer. J. Thorac. Oncol. 2018, 13, S320-S321. [CrossRef]

62. Pozzessere, C.; Bouchaab, H.; Jumeau, R.; Letovanec, I.; Daccord, C.; Bourhis, J.; Prior, J.O.; Peters, S.; Lazor, R.; Beigelman-Aubry, C. Relationship between Pneumonitis Induced by Immune Checkpoint Inhibitors and the Underlying Parenchymal Status: A Retrospective Study. ERJ Open Res. 2020, 6, 00165-02019. [CrossRef]

63. Sha, C.M.; Lehrer, E.J.; Hwang, C.; Trifiletti, D.M.; Mackley, H.B.; Drabick, J.J.; Zaorsky, N.G. Toxicity in Combination Immune Checkpoint Inhibitor and Radiation Therapy: A Systematic Review and Meta-Analysis. Radiother. Oncol. 2020, 151, 141-148. [CrossRef]

64. Quezada, S.A.; Peggs, K.S. Lost in Translation: Deciphering the Mechanism of Action of Anti-Human CTLA-4. Clin. Cancer Res. 2019, 25, 1130-1132. [CrossRef]

65. Simpson, T.R.; Li, F.; Montalvo-Ortiz, W.; Sepulveda, M.A.; Bergerhoff, K.; Arce, F.; Roddie, C.; Henry, J.Y.; Yagita, H.; Wolchok, J.D.; et al. Fc-Dependent Depletion of Tumor-Infiltrating Regulatory T Cells Co-Defines the Efficacy of Anti-CTLA-4 Therapy against Melanoma. J. Exp. Med. 2013, 210, 1695-1710. [CrossRef]

66. Vanpouille-Box, C.; Diamond, J.M.; Pilones, K.A.; Zavadil, J.; Babb, J.S.; Formenti, S.C.; Barcellos-Hoff, M.H.; Demaria, S. TGF $\beta$ Is a Master Regulator of Radiation Therapy-Induced Antitumor Immunity. Cancer Res. 2015, 75, 2232-2242. [CrossRef] [PubMed]

67. Young, K.H.; Baird, J.R.; Savage, T.; Cottam, B.; Friedman, D.; Bambina, S.; Messenheimer, D.J.; Fox, B.; Newell, P.; Bahjat, K.S.; et al. Optimizing Timing of Immunotherapy Improves Control of Tumors by Hypofractionated Radiation Therapy. PLoS ONE 2016, 11, e0157164. [CrossRef]

68. Barker, C.A.; Postow, M.A.; Khan, S.A.; Beal, K.; Parhar, P.K.; Yamada, Y.; Lee, N.Y.; Wolchok, J.D. Concurrent Radiotherapy and Ipilimumab Immunotherapy for Patients with Melanoma. Cancer Immunol. Res. 2013, 1, 92-98. [CrossRef] [PubMed]

69. Kwon, E.D.; Drake, C.G.; Scher, H.I.; Fizazi, K.; Bossi, A.; van den Eertwegh, A.J.M.; Krainer, M.; Houede, N.; Santos, R.; Mahammedi, H.; et al. Ipilimumab versus Placebo after Radiotherapy in Patients with Metastatic Castration-Resistant Prostate Cancer That Had Progressed after Docetaxel Chemotherapy (CA184-043): A Multicentre, Randomised, Double-Blind, Phase 3 Trial. Lancet Oncol. 2014, 15, 700-712. [CrossRef]

70. Tang, C.; Welsh, J.W.; de Groot, P.; Massarelli, E.; Chang, J.Y.; Hess, K.R.; Basu, S.; Curran, M.A.; Cabanillas, M.E.; Subbiah, V.; et al. Ipilimumab with Stereotactic Ablative Radiation Therapy: Phase I Results and Immunologic Correlates from Peripheral T Cells. Clin. Cancer Res. 2017, 23, 1388-1396. [CrossRef] [PubMed]

71. Verbrugge, I.; Hagekyriakou, J.; Sharp, L.L.; Galli, M.; West, A.; McLaughlin, N.M.; Duret, H.; Yagita, H.; Johnstone, R.W.; Smyth, M.J.; et al. Radiotherapy Increases the Permissiveness of Established Mammary Tumors to Rejection by Immunomodulatory Antibodies. Cancer Res. 2012, 72, 3163-3174. [CrossRef] [PubMed]

72. Cao, Y.; Li, W.; Wang, Z.; Pang, H. Potential and Unsolved Problems of Anti-PD-1/PD-L1 Therapy Combined with Radiotherapy. Tumori J. 2020. [CrossRef]

73. Hwang, W.L.; Pike, L.R.G.; Royce, T.J.; Mahal, B.A.; Loeffler, J.S. Safety of Combining Radiotherapy with Immune-Checkpoint Inhibition. Nat. Rev. Clin. Oncol. 2018, 15, 477-494. [CrossRef]

74. Deutsch, E.; Chargari, C.; Galluzzi, L.; Kroemer, G. Optimising Efficacy and Reducing Toxicity of Anticancer Radioimmunotherapy. Lancet Oncol. 2019, 20, e452-e463. [CrossRef]

75. Maker, A.V.; Yang, J.C.; Sherry, R.M.; Topalian, S.L.; Kammula, U.S.; Royal, R.E.; Hughes, M.; Yellin, M.J.; Haworth, L.R.; Levy, C.; et al. Intrapatient Dose Escalation of Anti-CTLA-4 Antibody in Patients with Metastatic Melanoma. J. Immunother. Hagerstown Md 1997 2006, 29, 455-463. [CrossRef] [PubMed]

76. Kim, J.E.; Patel, M.A.; Mangraviti, A.; Kim, E.S.; Theodros, D.; Velarde, E.; Liu, A.; Sankey, E.W.; Tam, A.; Xu, H.; et al. Combination Therapy with Anti-PD-1, Anti-TIM-3, and Focal Radiation Results in Regression of Murine Gliomas. Clin. Cancer Res. 2017, 23, 124-136. [CrossRef]

77. Dewan, M.Z.; Galloway, A.E.; Kawashima, N.; Dewyngaert, J.K.; Babb, J.S.; Formenti, S.C.; Demaria, S. Fractionated but Not Single-Dose Radiotherapy Induces an Immune-Mediated Abscopal Effect When Combined with Anti-CTLA-4 Antibody. Clin. Cancer Res. 2009, 15, 5379-5388. [CrossRef]

78. Lugade, A.A.; Moran, J.P.; Gerber, S.A.; Rose, R.C.; Frelinger, J.G.; Lord, E.M. Local Radiation Therapy of B16 Melanoma Tumors Increases the Generation of Tumor Antigen-Specific Effector Cells That Traffic to the Tumor. J. Immunol. 2005, 174, 7516-7523. [CrossRef]

79. Schaue, D.; Ratikan, J.A.; Iwamoto, K.S.; McBride, W.H. Maximizing Tumor Immunity With Fractionated Radiation. Int. J. Radiat. Oncol. 2012, 83, 1306-1310. [CrossRef]

80. Qin, Q.; Nan, X.; Miller, T.; Fisher, R.; Teh, B.; Pandita, S.; Farach, A.M.; Pingali, S.R.; Pandita, R.K.; Butler, E.B.; et al. Complete Local and Abscopal Responses from a Combination of Radiation and Nivolumab in Refractory Hodgkin's Lymphoma. Radiat. Res. 2018, 190, 322. [CrossRef] 
81. Quéro, L.; Gilardin, L.; Fumagalli, I.; Martin, V.; Guillerm, S.; Bauduceau, O.; Kirova, Y.M.; Hennequin, C.; Brice, P. AntiPD-1 Immunotherapy in Combination with Sequential Involved-Site Radiotherapy in Heavily Pretreated Refractory Hodgkin Lymphoma. Cancer/Radiothérapie 2019, 23, 132-137. [CrossRef]

82. Bernstein, M.B.; Krishnan, S.; Hodge, J.W.; Chang, J.Y. Immunotherapy and Stereotactic Ablative Radiotherapy (ISABR): A Curative Approach? Nat. Rev. Clin. Oncol. 2016, 13, 516-524. [CrossRef]

83. DeSelm, C.; Palomba, M.L.; Yahalom, J.; Hamieh, M.; Eyquem, J.; Rajasekhar, V.K.; Sadelain, M. Low-Dose Radiation Conditioning Enables CAR T Cells to Mitigate Antigen Escape. Mol. Ther. 2018, 26, 2542-2552. [CrossRef] [PubMed]

84. Deloch, L.; Derer, A.; Hartmann, J.; Frey, B.; Fietkau, R.; Gaipl, U.S. Modern Radiotherapy Concepts and the Impact of Radiation on Immune Activation. Front. Oncol. 2016, 6. [CrossRef]

85. Venkatesulu, B.P.; Mallick, S.; Lin, S.H.; Krishnan, S. A Systematic Review of the Influence of Radiation-Induced Lymphopenia on Survival Outcomes in Solid Tumors. Crit. Rev. Oncol. Hematol. 2018, 123, 42-51. [CrossRef]

86. Chen, D.; Verma, V.; Patel, R.R.; Barsoumian, H.B.; Cortez, M.A.; Welsh, J.W. Absolute Lymphocyte Count Predicts Abscopal Responses and Outcomes in Patients Receiving Combined Immunotherapy and Radiation Therapy: Analysis of 3 Phase 1/2 Trials. Int. J. Radiat. Oncol. 2020, 108, 196-203. [CrossRef]

87. Marciscano, A.E.; Ghasemzadeh, A.; Nirschl, T.R.; Theodros, D.; Kochel, C.M.; Francica, B.J.; Muroyama, Y.; Anders, R.A.; Sharabi, A.B.; Velarde, E.; et al. Elective Nodal Irradiation Attenuates the Combinatorial Efficacy of Stereotactic Radiation Therapy and Immunotherapy. Clin. Cancer Res. 2018, 24, 5058-5071. [CrossRef]

88. Golden, E.B.; Chhabra, A.; Chachoua, A.; Adams, S.; Donach, M.; Fenton-Kerimian, M.; Friedman, K.; Ponzo, F.; Babb, J.S.; Goldberg, J.; et al. Local Radiotherapy and Granulocyte-Macrophage Colony-Stimulating Factor to Generate Abscopal Responses in Patients with Metastatic Solid Tumours: A Proof-of-Principle Trial. Lancet Oncol. 2015, 16, 795-803. [CrossRef]

89. Liu, M.; Cai, X.; Zeng, Y. EP1.04-28 The Abscopal Effects of the Combination of Radiotherapy and GM-CSF for Patients with Metastatic Thoracic Cancers. J. Thorac. Oncol. 2019, 14, S980. [CrossRef]

90. Kwek, S.S.; Kahn, J.; Greaney, S.K.; Lewis, J.; Cha, E.; Zhang, L.; Weber, R.W.; Leonard, L.; Markovic, S.N.; Fong, L.; et al. GM-CSF and Ipilimumab Therapy in Metastatic Melanoma: Clinical Outcomes and Immunologic Responses. OncoImmunology 2016, 5, e1101204. [CrossRef]

91. Seung, S.K.; Curti, B.D.; Crittenden, M.; Walker, E.; Coffey, T.; Siebert, J.C.; Miller, W.; Payne, R.; Glenn, L.; Bageac, A.; et al. Phase 1 Study of Stereotactic Body Radiotherapy and Interleukin-2-Tumor and Immunological Responses. Sci. Transl. Med. 2012, 4, 137ra74. [CrossRef]

92. Bouquet, F.; Pal, A.; Pilones, K.A.; Demaria, S.; Hann, B.; Akhurst, R.J.; Babb, J.S.; Lonning, S.M.; DeWyngaert, J.K.; Formenti, S.C.; et al. TGF 1 Inhibition Increases the Radiosensitivity of Breast Cancer Cells In Vitro and Promotes Tumor Control by Radiation In Vivo. Clin. Cancer Res. 2011, 17, 6754-6765. [CrossRef] [PubMed]

93. Spiotto, M.; Fu, Y.-X.; Weichselbaum, R.R. The Intersection of Radiotherapy and Immunotherapy: Mechanisms and Clinical Implications. Sci. Immunol. 2016, 1, eaag1266. [CrossRef] [PubMed]

94. Rodríguez-Ruiz, M.E.; Rodríguez, I.; Mayorga, L.; Labiano, T.; Barbes, B.; Etxeberria, I.; Ponz-Sarvise, M.; Azpilikueta, A.; Bolaños, E.; Sanmamed, M.F.; et al. TGF $\beta$ Blockade Enhances Radiotherapy Abscopal Efficacy Effects in Combination with Anti-PD1 and Anti-CD137 Immunostimulatory Monoclonal Antibodies. Mol. Cancer Ther. 2019, 18, 621-631. [CrossRef]

95. Neelapu, S.S.; Tummala, S.; Kebriaei, P.; Wierda, W.; Gutierrez, C.; Locke, F.L.; Komanduri, K.V.; Lin, Y.; Jain, N.; Daver, N.; et al. Chimeric Antigen Receptor T-Cell Therapy-Assessment and Management of Toxicities. Nat. Rev. Clin. Oncol. 2018, 15, 47-62. [CrossRef] [PubMed] 